\title{
Effects of cimetidine and carbenoxolone on gastric mucus
}

\author{
M D ENE, J R CLAMP, AND C J C ROBERTS \\ From the Department of Medicine, University of Port Harcourt, Nigeria and Department of Medicine, Bristol \\ Royal Infirmary, Bristol
}

SUMMARY The effect of cimetidine on normal human gastric mucus has been compared with that of carbenoxolone, a drug believed to enhance mucus production. Each drug was given for two weeks, the gastric contents aspirated over a timed period and the results assessed in unstimulated and pentagastrin stimulated secretions. The volume, dry weight and the carbohydrate contents of nondiffusable glycoconjugates, high molecular mass glycoproteins and glycopolypeptides were investigated. Both drugs reduced the volumes of stimulated secretions. This was statistically significant after cimetidine. More importantly neither drug affected the amount of non-diffusable glycoconjugates, so that the concentration remained the same or increased. Both drugs reduced the monosaccharide content of the high molecular mass fractions. This reached significance for the stimulated secretion after cimetidine. As the carbohydrate content of the glycopolypeptides was unchanged this indicated the presence of a non-mucin glycoprotein or protein. Overall there was no fundamental difference between the results for cimetidine and carbenoxolone.

The mechanism by which carbenoxolone promotes ulcer healing remains obscure. It is believed to enhance mucus release thereby increasing mucosal resistance to acid, pepsin, and other harmful substances. Cimetidine, one of the more efficacious antiulcer drugs, acts by blocking $\mathrm{H}_{2}$-receptors. While most reviews record no effect on mucus, Guslandi et $a l^{1}$ suggest that recurrence of ulcers after cimetidine treatment was partly caused by the damaging effect on mucus.

In the living human subject, it is not possible to obtain adherent mucus except from gastrectomy specimens. Studies on gastric mucus in health and disease are usually carried out on aspirated material which contains other glycoconjugates and proteins. Many earlier studies of the effect of drugs on gastric mucus have measured concentrations of individual monosaccharides in the total secretion. It was decided therefore to use more specific techniques by carrying out a total carbohydrate analysis and by fractionating the aspirated material into its various components. This study therefore applied these procedures to evaluate the effects of chronic adminis-

Address for correspondence: Professor J R Clamp, Department of Medicine. University of Bristol, Bristol Royal Infirmary. Bristol BS2 8HW.

Received for publication 23 October 1987. tration of carbenoxolone or cimetidine on gastric mucus in normal human subjects.

\section{Methods}

\section{SUBJECTS}

Eight male and eight female subjects aged 18-28 years gave informed consent for the study which was approved by the ethical committee of the United Bristol Hospitals. The subjects were healthy, the women were not pregnant or lactating, and none were taking any drugs. Alcohol was not permitted for one week before, or during the study. The subjects were randomly allocated to two groups each consisting of four men and four women.

Each subject had gastric function studies carried out on two separate days. On the morning of the first study day, after an overnight fast, an orogastric tube was passed and its position verified by the water recovery test. ${ }^{2}$ The stomach was completely emptied over a 15 minute period and the aspirate discarded. Aspirates were then collected by continuous low pressure suction over 15 minute periods for 60 minutes (unstimulated secretion). Pentagastrin $6 \mu \mathrm{g} / \mathrm{kg}$ body weight was then administered subcutaneously and 15 minute collections continued for 
a further 120 minutes (stimulated secretion). One group of subjects then started 14 days' treatment with cimetidine ( $400 \mathrm{mg}$ twice a day) while the other had carbenoxolone sodium (100 mg twice a day). On the 14th day of treatment, after an overnight fast, the final dose of the appropriate drug was taken, and one hour later gastric aspiration carried out as above.

Each 15 minute sample was measured and neutralised with saturated sodium hydrogen carbonate solution. The unstimulated and stimulated collections were each pooled, dialysed and freeze dried (non-diffusable glycoconjugate). The dried material was weighed and subjected to gel permeation chromatography on a column of Sepharose CL-2B using as eluent $0.15 \mathrm{~mol} / \mathrm{l} \mathrm{NaCl}, 20 \mathrm{mmol} / \mathrm{l}$ sodium phosphate, $1 \% \mathrm{w} / \mathrm{v}$ SDS, $0 \cdot 02 \% \mathrm{w} / \mathrm{v} \mathrm{NaN}$, $\mathrm{pH} 7 \cdot 0$. The effluent was monitored for absorption at $280 \mathrm{~nm}$. In addition the hexose content of the effluent was estimated by the phenol-sulphuric acid method $^{3}$ and the tubes pooled according to the profile to give three fractions, representing excluded (S1), retarded (S2), and included (S3) material respectively. The high molecular mass fraction (S1) was exhaustively digested with pronase ${ }^{t}$ dialysed and subjected to gel permeation chromatography on a column of Sephadex G150. The effluent was monitored as before and pooled according to the profile to give three fractions namely S1 (glycopolypeptide), S2 (intermediate), and S3 (low) molecular mass fractions. Each fraction was dialysed and freeze dried.

The monosaccharide content of the various samples was determined by gas chromatography.' Results are given as mean (SE). Statistical analyses were done using the Student's paired $t$ test.

\section{Results}

Each Table gives the results from unstimulated and pentagastrin stimulated secretions. The effects of cimetidine and carbonoxolone on volume of secretions ( $\mathrm{ml} /$ hour) and the weight $(\mathrm{mg} / \mathrm{hour})$ of nondiffusable glycoconjugates are given in Tables 1 and 2 , together with the carbohydrate analyses of the

Table 1 Effect of two weeks cimetidine on the non-diffusable glycoconjugate content of gastric secretions

\begin{tabular}{|c|c|c|c|c|}
\hline & \multicolumn{2}{|l|}{ Unstimulated } & \multicolumn{2}{|l|}{ Stimulated } \\
\hline & Before & After & Before & After \\
\hline Volume $(\mathrm{ml} / \mathrm{h})$ & $41(6)$ & $39(6)$ & $104(11)$ & $81(8)^{*}$ \\
\hline Weight (mg/h) & $190(33)$ & $189(16)$ & $219(33)$ & $193(27)$ \\
\hline Concentration $(\mathrm{mg} / \mathrm{ml})$ & $4.81(0.56)$ & $4.79(0.64)$ & $2 \cdot 11(0 \cdot 29)$ & $2.41(0.26)$ \\
\hline \multicolumn{5}{|l|}{ Analysis (nmol/mg) } \\
\hline Mannose & $47(5)$ & $58(8)$ & $68(10)$ & $63(8)$ \\
\hline Galactose & $619(86)$ & $595(69)$ & $511(72)$ & $491(75)$ \\
\hline Glucose & $93(23)$ & $176(77)$ & $65(16)$ & $133(56)$ \\
\hline$N$-Acetylglucosamine & $359(53)$ & $393(52)$ & $388(47)$ & $382(63)$ \\
\hline$N$-Acetylgalactosamine & $189(17)$ & $210(32)$ & $195(22)$ & $207(37)$ \\
\hline Sialic acid & $54(10)$ & $52(13)$ & $48(12)$ & $51(10)$ \\
\hline
\end{tabular}

$\mathrm{n}=8$; mean $(\mathrm{SE}) ;{ }^{*} 2 \mathrm{p}<0 \cdot 05$.

Table 2 Effect of two weeks carbenoxolone on the non-diffusable glycoconjugate content of gastric secretions

\begin{tabular}{|c|c|c|c|c|}
\hline & \multicolumn{2}{|l|}{ Unstimulated } & \multicolumn{2}{|l|}{ Stimulated } \\
\hline & Before & After & Before & After \\
\hline Volume $(\mathrm{ml} / \mathrm{h})$ & $60(14)$ & $54(8)$ & $108(9)$ & $96(14)$ \\
\hline Weight (mg/h) & $176(17)$ & $207(19)$ & $177(14)$ & $185(14)$ \\
\hline Concentration $(\mathrm{mg} / \mathrm{ml})$ & $3.54(0.43)$ & $4.23(0.64)$ & $1 \cdot 81(0 \cdot 17)$ & $2.09(0.21)$ \\
\hline \multicolumn{5}{|l|}{ Analysis (nmol/mg) } \\
\hline Mannose & $70(13)$ & $62(11)$ & $67(6)$ & $79(9)$ \\
\hline Galactose & $583(57)$ & $513(62)$ & $450(73)$ & $582(69)$ \\
\hline Glucose & $80(10)$ & $285(130)$ & $88(14)$ & $105(27)$ \\
\hline$N$-Acetylglucosamine & $351(39)$ & $331(34)$ & $352(57)$ & $443(41)$ \\
\hline$N$-Acetylgalactosamine & $185(24)$ & $178(19)$ & $195(34)$ & $234(28)$ \\
\hline Sialic acid & $58(17)$ & $55(11)$ & $58(8)$ & $55(7)$ \\
\hline
\end{tabular}

$\mathrm{n}=8 ;$ mean $(\mathrm{SE})$. 
glycoconjugates. Cimetidine significantly reduced the volume of pentagastrin stimulated secretions but did not affect the weight of non-diffusable glycoconjugates. Thus the concentration $(\mathrm{mg} / \mathrm{ml})$ rose from $2 \cdot 11(0.29)$ before drug to $2.41(0 \cdot 26)$ after drug. Carbenoxolone had less effect; the corresponding figures being $1.81(0.17)$ and $2.09(0.21)$ which, however, did not reach significance. The carbohydrate content of non-diffusable glycoconjugates did not differ significantly between cimetidine and carbenoxolone.

The glycoconjugates were separated on Sepharose CL-2B, into high, intermediate and low molecular mass fractions ( $\mathrm{S} 1, \mathrm{~S} 2$, and $\mathrm{S} 3$ respectively). The percentage by weight of each fraction is given in Tables 3 and 4 with the monosaccharide composition of S1. Cimetidine and carbenoxolone reduced the carbohydrate content of S1 although this only reached significance with certain monosaccharides in the stimulated secretions after cimetidine. This was associated with an increase in the relative weight of the S1 fraction.

The S1 fraction is largely composed of high molecular mass glycoproteins but in order to obtain pure mucin derived material the fraction was exhaustively digested with a proteolytic enzyme (pronase). The glycopolypeptide derived from mucin is the only large molecule to survive this treatment ${ }^{6}$ and can be isolated by gel permeation chromatography using Sephadex G150. There were no significant differences between the effects of cimetidine and carbenoxolone on the glycopolypeptide fraction.

\section{Discussion}

Several methods have been used to study the effects of drugs on gastric mucus. Emmanouilidis $\mathrm{et} \mathrm{al}^{7}$ used a histochemical technique which involved staining

Table 3 Effect of two weekscimetidine on the Sepharose 2 B fractions of non-diffusable glycoconjugates from gastric secretion

\begin{tabular}{|c|c|c|c|c|}
\hline & \multicolumn{2}{|c|}{ Unstimulated } & \multicolumn{2}{|l|}{ Stimulated } \\
\hline & Before & After & Before & After \\
\hline \multicolumn{5}{|l|}{ Fractions (wt \%) } \\
\hline S1 & $27(3)$ & $22(3)$ & $25(4)$ & $35(4)^{*}$ \\
\hline S2 & $20(1)$ & $27(2)^{*}$ & $26(4)$ & $22(2)$ \\
\hline S3 & $54(2)$ & $52(3)$ & $49(5)$ & $43(3)$ \\
\hline \multicolumn{5}{|l|}{ Analysis of S1 (nmol/mg) } \\
\hline Fucose & $665(45)$ & $557(77)$ & $695(45)$ & $555(57)^{*}$ \\
\hline Mannose & $68(10)$ & $77(26)$ & $40(5)$ & $29(8)$ \\
\hline Galactose & $931(82)$ & $789(90)$ & $1034(74)$ & $794(84) \div$ \\
\hline Glucose & $171(22)$ & $235(68)$ & $123(25)$ & $81(15)$ \\
\hline $\mathrm{N}$-Acetylglucosamine & $615(53)$ & $467(60)$ & $691(79)$ & $554(66)$ \\
\hline $\mathrm{N}$-Acetylgalactosamine & $297(21)$ & $196(28)^{*}$ & $329(27)$ & $265(30)^{*}$ \\
\hline Sialic acid & $76(20)$ & $43(14)$ & $48(22)$ & $53(12)$ \\
\hline
\end{tabular}

$\mathrm{n}=8 ;$ mean $(\mathrm{SE}) ;{ }^{*} 2 \mathrm{p}<0 \cdot 05 ;+2 \mathrm{p}<0 \cdot 01$.

Table 4 Effect of two weeks carbenoxolone on the Sepharose $2 B$ fractions of non-diffusable glycoconjugates from gastric secretion

\begin{tabular}{|c|c|c|c|c|}
\hline & \multicolumn{2}{|c|}{ Unstimulated } & \multicolumn{2}{|l|}{ Stimulated } \\
\hline & Before & After & Before & After \\
\hline \multicolumn{5}{|l|}{ Fractions (wt \%) } \\
\hline S1 & $23(3)$ & $21(3)$ & $24(2)$ & $21(3)$ \\
\hline S2 & $29(2)$ & $26(3)$ & $27(3)$ & $28(4)$ \\
\hline S3 & $54(4)$ & $53(2)$ & $50(3)$ & $51(3)$ \\
\hline \multicolumn{5}{|l|}{ Analysis of $\mathrm{S} 1(\mathrm{nmol} / \mathrm{mg})$} \\
\hline Fucose & $563(81)$ & $475(49)$ & $694(68)$ & $648(80)$ \\
\hline Mannose & $41(14)$ & $57(17)$ & $48(16)$ & $50(11)$ \\
\hline Galactose & $848(92)$ & $729(67)$ & $1046(75)$ & $907(69)$ \\
\hline Glucose & $162(36)$ & $176(48)$ & $151(31)$ & $141(30)$ \\
\hline$N$-Acetylglucosamine & $602(64)$ & $445(49)^{*}$ & $664(63)$ & $583(51)$ \\
\hline$N$-Acetylgalactosamine & $257(39)$ & $193(25)$ & $305(40)$ & $243(20)$ \\
\hline Sialic acid & $70(22)$ & $27(14)$ & $50(14)$ & $39(13)$ \\
\hline
\end{tabular}

$\mathrm{n}=8 ;$ mean $(\mathrm{SE}) ;{ }^{*} 2 \mathrm{p}<0 \cdot 05$. 
biopsy specimens with periodic acid schiff and alcian blue reagents, and assessing the depth of staining. Another technique monitored the effects of drugs on the incorporation of labelled sugars into glycoproteins. ${ }^{x-10}$ The repeated biopsies and use of radioactive molecules have limited the application of these methods to human studies. On the other hand, biochemical methods have their limitations. First, they are undertaken on aspirated mucus which is assumed to have reached a steady state relationship with adherent mucus. Aspirated mucus contains a range of substances including cell breakdown products, non-mucus glycoconjugates, proteins, and so on. Analyses of single monosaccharides before and after therapy do not therefore necessarily reflect changes in mucus glycoproteins. This study has carried out comprehensive carbohydrate analyses on all the samples and fractions. In this way the relationships between the various monosaccharides enables the significance of each fraction to be assessed. For example $N$-acetylgalactosamine is characteristic of mucus glycoproteins whereas appreciable amounts of mannose indicates that non-mucin glycoproteins are present. In addition the non-diffusable glycoconjugates in the gastric aspirates were used for the isolation of a high molecular mass mucus glycoprotein fraction and for the preparation of mucus glycopolypeptides.

While there is little doubt about the effectiveness of carbenoxolone in healing gastric ulcers, its mechanism of action is uncertain. It reportedly increases the life span of gastric epithelial cells" and reduces the rate of loss of ${ }^{3} \mathrm{H}$-thymidine labelled gastric epithelial cells in acutely stressed rodents. ${ }^{12}$ Carbenoxolone has also been associated with changes in the monosaccharide content of aspirated gastric mucus. In view of the above comments, however, these findings must remain questionable. Guslandi and colleagues ${ }^{1314}$ studied the effect of various antiulcer drugs and concluded that carbenoxolone enhanced mucus whereas cimetidine damaged it and further suggested that this may be the reason for the relapses after cimetidine treatment. This work was, however, based on concepts published in $1967^{15}$ that gastric mucus can be separated into meaningful entities and that the acidic glycoproteins are more protective. Most biochemists in this field would not accept the simplicity of these ideas.

In the present study no important differences were

Table 5 Effect of two weeks cimetidine on the glycopolypeptide content of gastric secretions

\begin{tabular}{|c|c|c|c|c|}
\hline & \multicolumn{2}{|c|}{ Unstimulated } & \multicolumn{2}{|l|}{ Stimulated } \\
\hline & Before & After & Before & After \\
\hline $\begin{array}{l}\text { Subjects (n) } \\
\text { Analysis (nmol/mg) }\end{array}$ & 5 & 5 & 8 & 8 \\
\hline Fucose & $893(75)$ & $911(90)$ & $998(67)$ & $1088(59)$ \\
\hline Mannose & 0 & 0 & 0 & 0 \\
\hline Galactose & $1699(152)$ & $1628(88)$ & $1696(48)$ & $1646(60)$ \\
\hline Glucose & $88(25)$ & $94(12)$ & $53(11)$ & $59(18)$ \\
\hline$N$-Acetylglucosamine & $840(27)$ & $834(69)$ & $1024(43)$ & $1058(60)$ \\
\hline$N$-Acetylgalactosamine & $497(70)$ & $451(85)$ & $568(53)$ & $610(44)$ \\
\hline Sialic acid & $97(21)$ & $81(17)$ & $85(21)$ & $90(28)$ \\
\hline
\end{tabular}

Mean (SE). These analyses apply only to the material excluded (S1) from Sephadex G150 after pronase digestion.

Table 6 Effect of two weeks carbenoxolone on the glycopolypeptide content of gastric secretions

\begin{tabular}{|c|c|c|c|c|}
\hline & \multicolumn{2}{|c|}{ Unstimulated } & \multicolumn{2}{|l|}{ Stimulated } \\
\hline & Before & After & Before & After \\
\hline $\begin{array}{l}\text { Subjects (n) } \\
\text { Analysis (nmol/mg) }\end{array}$ & 8 & 8 & 7 & 7 \\
\hline Fucose & $805(41)$ & $883(74)$ & $971(122)$ & $1017(94)$ \\
\hline Mannose & 0 & 0 & 0 & 0 \\
\hline Galactose & $1797(112)$ & $1675(110)$ & $1550(78)$ & $1673(73)$ \\
\hline Glucose & $99(9)$ & $69(23)$ & $53(16)$ & $65(19)$ \\
\hline$N$-Acetylglucosamine & $820(57)$ & $972(80)$ & $1032(59)$ & $1158(67)$ \\
\hline$N$-Acetylgalactosamine & $375(37)$ & $518(56)^{*}$ & $547(30)$ & $603(33)$ \\
\hline Sialic acid & $95(22)$ & $106(24)$ & $123(17)$ & $120(11)$ \\
\hline
\end{tabular}

Mean (SE); ${ }^{*} 2 \mathrm{p}<0 \cdot 05$. These analyses apply only to the material excluded (S1) from Sephadex $G 150$ after pronase digestion. 
found between the results for cimetidine and carbenoxolone. Both drugs reduced the volume of pentagastrin stimulated secretions but had no effect on the content of non-diffusable glycoconjugates. Because the glycoconjugates are an indirect measure of mucus glycoproteins neither drug appears to affect the quantitative aspects of mucus secretion. The acidic fraction mentioned above would depend on sialic acid content, but Tables 1 and 2 show that cimetidine does not reduce the amount of sialic acid in the glycoconjugate fraction. Indeed there were no significant differences between the two drugs as far as this monosaccharide is concerned.

The results of separating the glycoconjugates into various sized fractions are shown in Tables 3 and 4. Cimetidine caused an increase in the larger fractions - namely, S2 in unstimulated secretions and S1 in stimulated secretions. This could be because of a decrease in peptic activity and might theoretically lead to an enhancement in the 'quality' of the mucus layer. Both cimetidine and carbenoxolone cause an apparent reduction in the carbohydrate content of the high molecular mass fraction (S1) as shown in Tables 3 and 4 , which reaches significance in the stimulated secretion after cimetidine. The lower content of carbohydrate in S1 could be the result of smaller oligosaccharide units in the mucus glycoproteins or to the presence of an increased amount of a non-mucin component. The results in Tables 5 and 6 , however, show that the carbohydrate of mucus glycopolypeptide is not decreased after administration of the two drugs, excluding the first of these two possibilities. The likelihood is therefore that a nonmucin component is present. Several proteins have been described in association with mucus some of which are important in the polymeric structure. ${ }^{16}$ In support of this, the $280 \mathrm{~nm}$ absorption characteristic of protein was increased in the S1 fraction after both drugs but to a greater extent with cimetidine.

The analyses of the glycopolypeptides are given in Tables 5 and 6 . The only significant difference is in the $\mathrm{N}$-acetylgalactosamine content after carbenoxolone in the unstimulated secretions. The result before drug (Table 6) is, however, anomalously low whereas the after drug result is comparable with the other analyses. The interpretation of this change is therefore difficult. The results obtained for carbenoxolone are interesting in view of the suggestions that a major mode of action of this drug is by enhancement of the mucus barrier. ${ }^{1718}$ No important differences were found between before drug results and after drug nor between carbenoxolone and cimetidine. The assertion that cimetidine damages mucus ${ }^{1314}$ is not supported by any of these results.

This study was carried out to assess the effect of two important ulcer-healing drugs on gastric mucus in normal subjects. The lack of spectacular results must be interpreted in terms of individuals who are already fully 'cytoprotected' and who would not be expected to show marked changes. The study does nevertheless provide a baseline for the investigation of patients with peptic ulcer in whom the mucus layer might be defective and which might be restored to normal by the drugs.

This study was supported by a grant from Smith Kline \& French Laboratories Ltd. We would like to thank Jill Locke-Edmunds and David Hepper for technical assistance, and Victoria Blake for secretarial help.

\section{References}

1 Guslandi M, Tittobello A, Evangelista A, Fesce E, Cambielli M. Cimetidine and protective effect of mucus in gastric ulcer. $\mathrm{Br}$ Med J 1978; i: 1486.

2 Hassan M, Hobsley M. Positioning of subject and of nasogastric tube during a gastric secretion study. $\mathrm{Br} \mathrm{Med}$ $J$ 1970; i: 458-60.

3 Dubois M, Gilles KA, Hamilton JK, Rebers PA, Smith F. Colorimetric method for determination of sugars and related substances. Anal Chem 1956; 28: 350-6.

4 Clamp JR, Fraser G, Read AE. Study of the carbohydrate content of mucus glycoproteins from normal and diseased colons. Clin Sci 1981; 61: 229-34.

5 Clamp JR. A gas-liquid chromatographic approach to the analysis of carbohydrates. Biochem Soc Trans 1977; 5: $1693-5$.

6 Creeth JM. Constituents of mucus and their separation. Br Med Bull 1978; 34: 17-14.

7 Emmanouilidis A, Nicolopoulou-Stamati P, Manousos $O$. Effect of cimetidine and oxmetidine on the parietal cell population, gastric mucosal glycoproteins and surface gastric epithelium in duodenal ulcer patients. $J$ Intern Med Res 1982; 10: 113-7.

8 Shillingford JS. The effect of carbenoxolone and other drugs on the gastric and duodenal mucosa. University of Surrey: PhD Thesis, 1975.

9 Dekanski JB, MacDonald A, Sacra P, Parke DV. Effects of fasting, stress and drugs on gastric glycoprotein synthesis in the rat. BrJ Pharmacol 1975; 55: 387-92.

10 Parke DV. Gastric mucus and carbenoxolone. In: Truelove SC, Ritchie JA, eds. Topics in gastroenterology 4. Oxford: Blackwell Scientific Publications, 1976: 329-43.

11 Lipkin M. Carbenoxolone sodium and the rate of extrusion of gastric epithelial cells. In: Baron $\mathbf{J H}$, Sullivan FM, eds. Carbenoxolone sodium. London: Butterworths, 1970: 11.

12 Lipkin M. Cell proliferation and carbenoxolone. In: Beck IT, ed. North American symposium on carbenoxolone. Amsterdam: Excerpta Medica, 1976: 57.

13 Guslandi M, Cambielli M, Bierti L, Tittobello A. Effect of carbenoxolone and cimetidine on gastric mucin. Clin Ther 1980; 3: 40-2.

14 Guslandi M, Cambielli M, Bierti L, Tittobello A. 
Relapse of duodenal ulceration after cimetidine treatment. Br Med J 1978; i: 718.

15 Jerzy Glass GB. Current status of the "glandular mucoprotein" and "mucoproteose" fractions of gastric mucin: a review of 15 years progress in this area. Ann NY Acad Sci 1967; 140: 804-34.

16 Pearson JP, Allen A, Parry S. A 70000-molecularweight protein isolated from purified pig gastric mucus glycoprotein by reduction of disulphide bridges and its implication in the polymeric structure. Biochem $J 1981$; 197: $155-62$.

17 Domschke W, Domschke S, Classen M, Demling L. Some properties of mucus in patients with gastric ulcer. Effect of treatment with carbenoxolone sodium. Scan J Gastroenterol, 1972; 7: 647-51.

18 Goodier TEW. In: Avery-Jones F, Parke DV, eds. A symposium on carbenoxolone. London: Butterworths. 1975: 273. 